\title{
A Preliminary Near-Infrared Spectroscopy Study in Adolescent and Adult Patients with Attention-Deficit/Hyperactivity Disorder Symptoms
}

\author{
Tomohiko Matsuo ${ }^{1,2}$, Sachie Oshima1, Yasuto Kunii', Takaaki Okano², Hirooki Yabe1, \\ Shinichi Niwa ${ }^{3}$ \\ ${ }^{1}$ Department of Neuropsychiatry, School of Medicine, Fukushima Medical University, Fukushima, Japan \\ ${ }^{2}$ Kumamoto Medical Clinic for Psychosomatic Medicine and Psychiatry, Kumamoto, Japan \\ ${ }^{3}$ Department of Psychiatry, Aizu Medical Center, School of Medicine, Fukushima Medical University, \\ Fukushima, Japan \\ Email: ${ }^{*}$ tmhk mtsw13@msn.com
}

Received 6 August 2014; revised 5 September 2014; accepted 8 October 2014

Copyright (C 2014 by authors and Scientific Research Publishing Inc.

This work is licensed under the Creative Commons Attribution International License (CC BY).

http://creativecommons.org/licenses/by/4.0/

(c) (i) Open Access

\begin{abstract}
Prefrontal dysfunction in patients with attention-deficit/hyperactivity disorder (AD/HD) has been repeatedly detected on a behavioral level, and various brain-imaging studies have elucidated the pathophysiology of AD/HD. Recent advances in near-infrared spectroscopy (NIRS) have enabled noninvasive investigations of brain function in various mental disorders, especially major depression, schizophrenia, and bipolar disorder. The objective of this preliminary study was to use NIRS to evaluate changes in frontal lobe blood flow in post childhood or adult patients with AD/HD symptoms. The subjects included five patients with a range of mental disorders and AD/HD symptoms, and a matched (age, sex, and dominant hand) control group of five healthy subjects. We compared the changes in cerebral blood flow during verbal fluency tasks between the two groups. The duration of the elevated oxygenated hemoglobin was notably shorter in the AD/HD group than that in the healthy control group. We suggest that the shorter elevation durations of oxygenated hemoglobin concentrations might be a biological indicator for post childhood or adult AD/HD or of impaired executive functioning.
\end{abstract}

\section{Keywords}

Adult, Attention-Deficit/Hyperactivity Disorder, Executive Function, Near-Infrared Spectroscopy, Verbal Fluency Task

\footnotetext{
${ }^{*}$ Corresponding author.
}

How to cite this paper: Matsuo, T., Oshima, S., Kunii, Y., Okano, T., Yabe, H. and Niwa, S. (2014) A Preliminary Near-Infrared Spectroscopy Study in Adolescent and Adult Patients with Attention-Deficit/Hyperactivity Disorder Symptoms. Open Journal of Psychiatry, 4, 396-404. http://dx.doi.org/10.4236/ojpsych.2014.44046 


\section{Introduction}

Barkley considered the essence of attention-deficit/hyperactivity disorder (AD/HD) to be "an impairment of behavioral control”, that is, executive function impairment [1]. Executive function impairment presents as behaviors, and the affected patients cannot perform functions related to goal setting and planning, plan execution, or action selection. In other words, the condition is characterized by impaired behavioral control that prevents patients from converting their intent into the corresponding action.

$\mathrm{AD} / \mathrm{HD}$ symptoms are innate and continue to manifest as behavioral characteristics in some way or another throughout an individual's life. AD/HD is a common neuropsychiatric disorder, with accumulating data suggesting that $\mathrm{AD} / \mathrm{HD}$ is evident in about $2 \%-6 \%$ of adults [2]. Furthermore, prominent $\mathrm{AD} / \mathrm{HD}$ symptoms persist into young adulthood in approximately one-half of childhood cases [3], and it is not uncommon for these tendencies to continue beyond childhood and into adolescence/adulthood as the basis for other mental diseases such as personality disorders [4] [5]. In post childhood AD/HD, hyperactivity and impulsivity become less prominent, while inattention characteristics become pronounced [6]. In addition to a natural impulsivity, repeated experiences of injury in early childhood result in a lack of confidence or strong anxiety and compulsive tendencies [7]. Furthermore, a combination of major depression and AD/HD is seen in a certain proportion of cases. Biederman et al. detailed an 11-year longitudinal case-control study in which the hazard ratios for the prevalence of disorders in girls with AD/HD compared to in healthy girls were 7.2 for antisocial disorders, 6.8 for mood disorders, 2.1 for anxiety disorders, 3.2 for developmental disorders, 2.7 for substance dependency disorders, and 3.5 for eating disorders [8]. These results demonstrate that for girls with $\mathrm{AD} / \mathrm{HD}$, the risk of suffering from one of the listed disorders by young adulthood is significantly higher than that for healthy girls. Similar reports have been published regarding boys with AD/HD [9]. This accumulation of various mental diseases in addition to the innate developmental characteristics makes the diagnosis of AD/HD difficult in adults [10]. For this reason, pressure is mounting for the establishment of a biological indicator for diagnosing AD/HD.

Methylphenidate, which has been used as a therapeutic drug, selectively targets dopamine and noradrenaline transporters and supposedly activates dopamine and noradrenaline receptors in order to increase attention levels [11]. For this reason, AD/HD symptoms are thought to be related to the frontostriatal circuitry [12]. Many studies have utilized tasks that depend on inhibitory reactions (e.g., go/no go task) and compared the brain activation of patients with AD/HD to that of healthy subjects. Rubia et al. observed decreased activity in the right medial prefrontal cortex, right inferior frontal cortex, and left caudate nucleus in a functional magnetic resonance imaging (fMRI) study of patients with AD/HD who were around 15 years of age [13]. Structural MRI studies have reported a reduction in volume in the subcortical circuits, including the frontal lobes and the caudate nucleus [14]-[23]. In addition, morphological abnormalities in the cerebellum have also been noted [15] [16] [23]-[28], with a hypothesized abnormality of the cerebellum-thalamus-frontal lobe system [26] [29]. In addition, the cerebral volume of patients with $\mathrm{AD} / \mathrm{HD}$ was reported to be approximately $3 \%-5 \%$ less than that of the control group. Regional cerebral blood flow studies using single-photon emission computed tomography showed reduced blood flow in the right lateral prefrontal cortex, right middle temporal gyrus, and both sides of the cerebellar cortex in patients with AD/HD [30]. Collectively, these studies support frontostriatal circuitry involvement in $\mathrm{AD} / \mathrm{HD}$.

Because of its prevalence and seriousness, diagnosing $\mathrm{AD} / \mathrm{HD}$ in adulthood is important. However, a clear biological indicator does not exist. While brain imaging studies using fMRI and positron emission tomography (PET) have found structural abnormalities and reduced functional activity in AD/HD patients, imaging with these modalities has the disadvantage of requiring large devices and long imaging times. On the other hand, near-infrared spectroscopy (NIRS) enables noninvasive, bedside, and brief measurement of regional cerebral blood volume; thus, we chose to use NIRS in the present study. This method utilizes the features of near infrared light in order to measure the oxygenated/deoxygenated hemoglobin (oxyHb/deoxyHb) concentrations inside tissues. The relevant features of near-infrared light include the ability to penetrate biological tissues with relative ease and the unique way in which it is absorbed by hemoglobin in the blood. There is a close correlation between neural activity in the cerebral cortex and local hemodynamics, with changes arising in oxyHb/deoxyHbconcentrations in areas demonstrating functional brain activation [31]. Therefore, by capturing the changes in light absorption in various brain tissues, we can understand the activation state of the brain. The objective of this preliminary study was to use NIRS to investigate changes in frontal lobe blood flow in patients with post childhood AD/HD symptoms. Additionally, the adequacy of NIRS as a biological indicator for diagnosing adults 
with $\mathrm{AD} / \mathrm{HD}$ was investigated.

\section{Methods}

\subsection{Subjects}

The subjects included five patients with a range of mental diseases and AD/HD symptoms, and a control group of five healthy individuals matched for age, sex, and dominant hand (Table 1). The subjects consisted of one male and five female patients, with an age range of 17 to 53 years (mean age \pm standard deviation [SD], $33.2 \pm$ 12.7 years). The subjects were selected from patients attending outpatient or inpatient therapy at the Department of Neuropsychiatry, Fukushima Medical University Hospital. The AD/HD symptoms of the subjects were ascertained using the Adult AD/HD Self-Report Scale-V1.1 (ASRS-V1.1).

The healthy control group was recruited from among the medical staff and students at the same hospital, and none of the control subjects was suffering from any mental diseases.

\subsection{The ASRS-V1.1 Screener}

The ASRS is a self-administered screening scale for adult AD/HD that was created at the same time as the revision of the World Health Organization Composite International Diagnostic Interview. The ASRS-V1.1 includes 18 questions that conform to Item A of the diagnostic criteria for AD/HD in the Diagnostic and Statistical Manual of Mental Disorders, Fourth Edition. The screener includes six of these items (4 inattention items and 2 hyperactivity/impulsivity items). Each question can be answered on a 5-point Likert scale, based on a scale of frequency ranging from "never" to "very often". Answers are scored as either positive or negative. The threshold is different for different questions. Answers of "never" and "rarely" are always scored as negative, answers of "often" and "very often" are always scored as positive, and answers of "sometimes" are scored positively in only three of the six questions. Four or more positive answers are indicative of AD/HD symptoms.

The sensitivity, specificity, and classification accuracy of this screening test are $68.7 \%$, $99.5 \%$, and $97.9 \%$, respectively [32].

Table 1. Characteristics of the control subjects and patients with AD/HD symptoms.

\begin{tabular}{ccccccc}
\hline Patient No. & Age (years) & Sex & Diagnosis & Laterality & Verbal fluency & Medications (mg/day) \\
\hline 1 & 35 & F & BPD & Right & 12 & FLV 150, TZD 50, VPA 800, FLU 1 \\
2 & 53 & F & MD & Left & 11 & FLV 100, VPA 600, PPZ 6, ELZ 1 \\
3 & 17 & F & PDD NOS & Right & 9 & TZD 50, OLZ 10, LZP 1.5, FLU 2 \\
4 & 39 & M & PD & Right & 10 & PXT 40, TZD 100, APZ 6, ETZ 6, BRZ \\
5 & 24 & M & PDD NOS & Right & 11 & RIS 2, CPZ 100, ZOL 5 \\
Mean \pm SD & $33.2 \pm 12.7$ & & & & $10.6 \pm 0.9$ & - \\
Control No. & & & & & & - \\
1 & 32 & F & - & Right & 15 & - \\
2 & 49 & F & - & Right & 16 & - \\
3 & 19 & F & - & Right & 16 & - \\
4 & 41 & F & - & Right & 17 & \\
5 & 24 & M & - & Right & 19 & \\
Mean \pm SD & $32.6 \pm 14.9$ & & & & &
\end{tabular}

AD/HD: Attention-deficit/hyperactivity disorder; SD: Standard deviation; F: Female; M: Male; BPD: Borderline personality disorder; MD: Major depressive disorder; PDD NOS: Pervasive developmental disorder not otherwise specified; PD: Pain disorder; FLV: Fluvoxamin; TZD: Trazodone; VPA: Valproic acid; FLU: Flunitrazepam; PPZ: Perphenazine; ELZ: Ethyl loflazepate; OLZ: Olanzapine; LZP: Lorazepam; PXT: Paroxetine; APZ: Aripiprazole; ETZ: Etizolam; BRZ: Brotizolam; RIS: Risperidone; CPZ: Chlorpromazine; ZOL: Zolpidem; NS: Not significant ( $p>0.10)$. 


\subsection{Activation Tasks}

Changes in cerebral blood flow during verbal fluency tasks were compared between the two groups. The verbal fluency task is a test of cognitive activity that can be executed successfully by most sufferers of mental disease, and as such, is thought to be an appropriate cognitive load. The subjects were directed to change the first letter of a word every 20 s while performing a 60-s verbal fluency task, as in Suto et al. [33]. The tasks were set so that the scores of the patient group would not be too low. Previous studies have thus far been unable to observe a significant correlation between the performance scores for this task and NIRS signals. Verbal fluency tasks require the following cognitive functions: 1) summoning the words for the answer from long-term memory; 2) memorizing which words were already given as answers using working memory; 3) suppressing inappropriate words; and 4) maintaining concentration [34]. Other tests, including fMRI and PET, are also known to show clear, broad-spectrum frontal lobe activity [35] [36]. The vowel sounds a, e, i, o, and u were repetitively uttered before and after the task as a baseline task, in order to investigate the pattern of change between the baseline task and the cognitive task by allowing for the subtraction of brain activity caused by articulation.

\subsection{NIRS}

An ETG-4000 device made by Hitachi Medical Corporation was used to measure changes in oxyHb and deoxyHb in the frontal region while the participants performed the verbal fluency tasks. The near-infrared light was in the wavelength range of 650 - $1000 \mathrm{~nm}$, which extends from visible light to infrared light. Since the absorptions of oxyHb and deoxyHb differ according to the near-infrared light wavelength, it is possible to calculate their respective concentrations. Near-infrared light, when applied to the scalp with optical fibers, penetrates to a depth of $20-30 \mathrm{~mm}$, where it disperses and reflects diffusely. The light that bounces back to the scalp is detected by the optical fiber. The obtained NIRS signals are thought to reflect cerebral blood volume [37], and measurable changes in hemoglobin concentrations are thought to parallel cerebral blood flow [38].

The advantages of NIRS over other functional brain imaging techniques are as follows: 1) It is noninvasive; 2) It is minimally restrictive; 3) There are no loud noises, feelings of enclosure, or exposure to radiation or to high magnetic fields; 4) Measurements can be easily repeated; 5) The equipment is compact and portable; 6) The temporal resolution is high.

The limitations of NIRS are as follows: 1) The measured changes in concentration are confounded by blood volume changes; 2) Measurement of deep brain structures is not possible; 3) The spatial resolution is low.

\subsection{Statistical Analysis}

For each subject, the 60-s task was divided into three 20-s intervals (first, middle, and last 20-s interval), and the average score for each interval was calculated. A healthy control vs. AD/HD t-test was performed for each interval on the NIRS signals and task performance scores. Finally, an investigation was carried out to determine the correlation between the cerebral changes during task performance in the AD/HD group and the average score for an interval.

\section{Results}

The number of words generated during the verbal fluency task showed no significant differences between the two groups (mean $\pm \mathrm{SD}$; patient group: $10.6 \pm 0.9$, controls: $16.6 \pm 1.1$ ) (Table 1 ).

We produced grand average waveforms of changes in oxyHb during cognitive activation in the AD/HD (black line in Figure 1) and control (red line in Figure 1) groups for all measurement locations on the subjects' heads. In the control group, oxyHb increases were observed during the task period. Particularly in the frontal channels, oxyHb rapidly increased immediately after the start of the task period. Subsequently, it was maintained at the activated level, and decreased gradually after the task was finished. Meanwhile, in the AD/HD group, oxyHb increases during the task period were smaller than the oxyHb increases in the control group for both the frontal and temporal channels. Differences between the groups were especially pronounced after the middle of the task period.

A t-test to measure interval-by-interval differences between the AD/HD and normal control groups showed a significant difference in the temporal region on both sides, particularly after the middle interval of the task (Figure 2). In the first interval, we found only two channels in the left lower temporal region (channels 40 and 

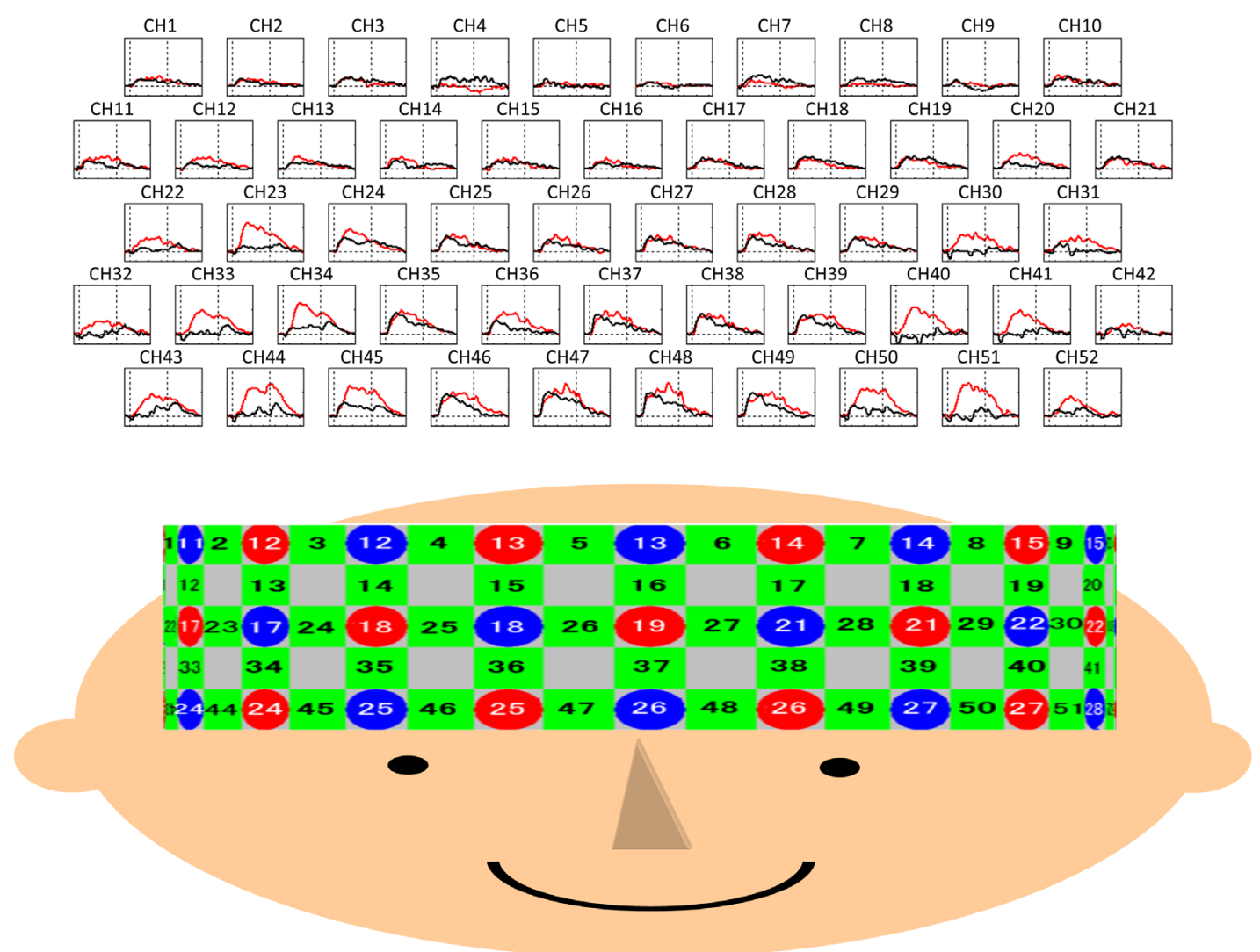

Figure 1. Grand-average waveforms of oxyhemoglobin concentration changes during cognitive activation in the two groups (red line: healthy controls, 5 subjects; black line: attention-deficit/hyperactivity disorder, 5 subjects). These average waveforms change during cognitive activation, which is the period between the two vertical dashed lines.

First interval (0-20s)

tvalue

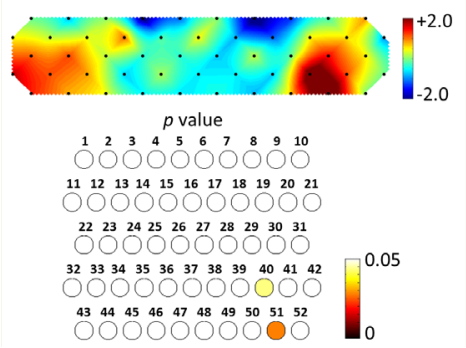

Middle interval (20-40 s)

$t$ value

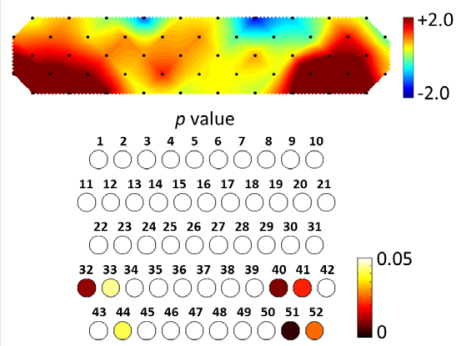

Last interval (40-60 s)

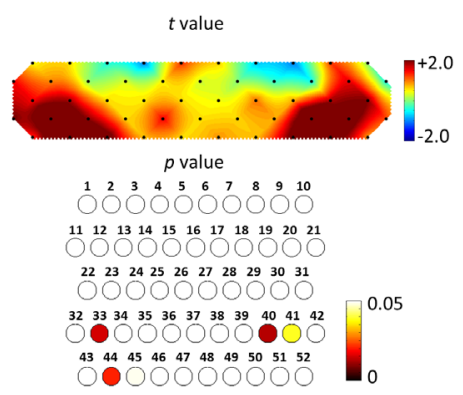

Figure 2. Topographic presentation of the $t$ - and $p$-values of the oxyhemoglobin comparisons between the attention-deficit/hyperactivity group and the healthy control group during each of the three sub-intervals within the task-execution period. A significant difference $(p<0.05)$ is seen in the left and right temporal areas, especially during the middle sub-interval (20 - 40 s).

51, $p<0.05)$ that showed a statistically significant difference. In the middle interval, significant differences were observed in seven channels (right lower temporal region, channels 32, 33, and 34, $p<0.05$; left lower temporal region, channels 40, 41, and 52, $p<0.05$; channel 51, $p<0.01$ ). In the last interval, we found significant differences in four channels on both sides of the lower temporal region (channels 33, 40, 41, and 44, $p<$ 0.05). The same maximum increase in oxyHb concentration was observed in both groups, but compared to the healthy control group, the activity in the $\mathrm{AD} / \mathrm{HD}$ group occurred for a shorter duration, and subsequent varia- 
tions were minimal.

Investigations of the correlations between task performance in the AD/HD group and the mean oxyHb concentrations, broken down by interval, showed negative correlations, although only a few channels reached significance (channels 5 and 52, first interval, $p<0.05$; channel 15, middle interval, $p<0.05$ ) (Figure 3). In other words, poorer task performances were associated with a rise in oxyHb concentrations.

\section{Discussion}

Few studies have been conducted on AD/HD using NIRS. In a verbal fluency study conducted on adults with primarily mixed-type $\mathrm{AD} / \mathrm{HD}$, the task performance scores in patients with $\mathrm{AD} / \mathrm{HD}$ were equal to those of the control group (in letter fluency) or higher (in meaning fluency), although the increase in oxyHb in the prefrontal cortex following the task was less in subjects with AD/HD than in the control group [39]. In a study by the same group that investigated loaded working memory [40], the increase in oxyHb in the ventrolateral prefrontal cortex was less for the AD/HD group than for the control group. Hemodynamically, this suggests a drop in activity in the prefrontal cortex. However, functionally, it was clear that there was no drop in the subjects' ability to perform the tasks [40].

The short-term drop in oxyHb concentrations observed in the frontal lobes in this study could correspond to impairments in behavioral suppression. That is, since oxyHb concentrations in this group cannot be maintained over long periods while performing tasks, this suggests that the workings of the frontostriatal circuitry might be impaired, which could result in behavioral suppression impairments. Shecklmann et al. [39] have interpreted the phenomenon in which the number of words generated is significantly higher for the AD/HD group, despite a drop in blood flow, as being correlated with the observed AD/HD phenomenon of hyperfocusing. However, the number of words generated in the AD/HD group in the present study tended to be smaller, although the difference was not significant. This may be attributable to the influence of complications from other diseases. In addition, when the same group had participants perform a working memory task (n-back task), the oxyHb increase in the ventrolateral prefrontal cortex for the AD/HD group was less than that in the control group [40]. It is interesting that in both cases, while the hemodynamics suggested a drop in activity in the prefrontal area, there was not necessarily any drop in function. Moreover, in the present study, the same tendencies were observed across a range of ages and diseases.

Future studies compiling the NIRS profiles of both children and adults with AD/HD are needed to determine whether the NIRS profiles revealed in this study are consistent from childhood or whether they change after reaching maturity, and whether they are influenced by secondary disorders and complications. Moreover, while differences in AD/HD phenotypes were not taken into consideration in this study, a study into the potential dependence of NIRS profiles on the AD/HD phenotype of the patient is necessary.

The greatest limitation of this study was the small number of patients. Moreover, because it was not a syste-

First interval (0-20 s)

$r$ value

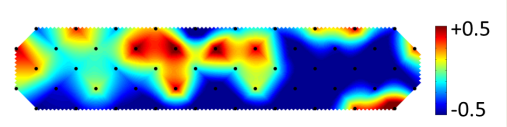

$p$ value

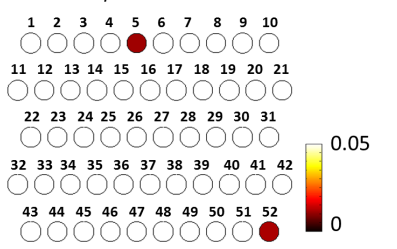

Middle interval (20-40 s)

$r$ value

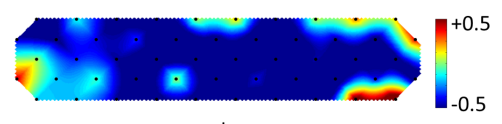

$p$ value

$12 \bigcirc^{3} \bigcirc^{5} \bigcirc^{6} \bigcirc^{7} \bigcirc^{8} \bigcirc^{9} \bigcirc^{10}$

$\begin{array}{ll}11 & 12 \quad 131415 \quad 1617 \quad 18192021\end{array}$

1112131415161718192021

$22 \quad 2324252627282930 \quad 31$

0000000000

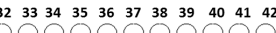

43444546474849505152
Last interval (40-60 s)

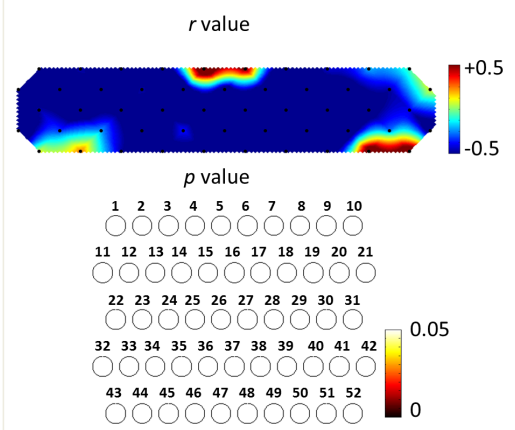

Figure 3. Correlation between cerebral blood flow changes in the attention-deficit/hyperactivity disorder (AD/HD) group and the mean scores on the Adult AD/HD Self-Report Scale-V1.1, a self-administered screening scale for adult AD/HD. There are only a few significant channels, but a negative correlation is seen between task-performance-induced cerebral activation and the mean score. In other words, higher brain activity was associated with lower performances. These findings are in agreement with Schecklmann et al. [39]. 
matic study, other issues were present including patient selection issues caused by a lack of confirmed $\mathrm{AD} / \mathrm{HD}$ diagnoses. Moreover, the potential influence of complications, comorbidities, and medication could not be excluded.

\section{Conclusion}

In summary, the present study evaluated cerebral blood flow in patients of various ages with AD/HD symptoms and a range of different diagnoses during a verbal fluency task. Similar NIRS profiles were observed in these patients. The findings of this research are consistent with those of many previous studies using other measurement techniques. The NIRS activity profiles revealed in this study may be specifically related to the severity of $\mathrm{AD} / \mathrm{HD}$ symptoms and could be used as a potential biological indicator for diagnosing $\mathrm{AD} / \mathrm{HD}$.

\section{Acknowledgements}

We would like to thank all of the subjects who participated in this study for the time and effort they devoted to the NIRS investigation. All authors declare that they have no biomedical financial interests or potential conflicts of interest. We have no sources of funding to declare.

\section{References}

[1] Barkley, R.A. (1997) Attention-Deficit/Hyperactivity Disorder, Self-Regulation, and Time: Toward a More Comprehensive Theory. Journal of Developmental and Behavioral Pediatrics, 18, 271-279. http://dx.doi.org/10.1097/00004703-199708000-00009

[2] Wender, P.H., Wolf, L.E. and Wasserstein, J. (2001) Adults with AD/HD. An Overview. Annals of the New York Academy of Sciences, 931, 1-16. http://dx.doi.org/10.1111/j.1749-6632.2001.tb05770.x

[3] Biederman, J., Mick, E. and Faraone, S.V. (2000) Age-Dependent Decline of Symptoms of Attention Deficit Hyperactivity Disorder: Impact of Remission Definition and Symptom Type. The American Journal of Psychiatry, 157, 816818. http://dx.doi.org/10.1176/appi.ajp.157.5.816

[4] Weiss, M. and Weiss, G. (2002) Attention Deficit Hyperactivity Disorder. In: Lewis, M., Ed., Child and Adolescent Psychiatry. A Comprehensive Textbook, 3rd Edition, Lippincott, Williams, \& Wilkins, Philadelphia, 645-670.

[5] Fossati, A., Novella, L., Donati, D., Donini, M. and Maffei, C. (2002) History of Childhood Attention Deficit/Hyperactivity Disorder Symptoms and Borderline Personality Disorder: A Controlled Study. Comprehensive Psychiatry, 43, 369-337. http://dx.doi.org/10.1053/comp.2002.34634

[6] Dulcan, M. (1997) Practice Parameters for the Assessment and Treatment of Children, Adolescents, and Adults with Attention-Deficit/Hyperactivity Disorder. American Academy of Child and Adolescent Psychiatry. Journal of the American Academy of Child and Adolescent Psychiatry, 36, 85S-121S. http://dx.doi.org/10.1097/00004583-199710001-00007

[7] Weiss, G. and Hechtman, L. (1986) Hyperactive Children Grown Up. Guilford Press, New York.

[8] Biederman, J., Petty, C.R., Monuteaux, M.C., Fried, R., Byrne, D., Mirto, T., et al. (2010) Adult Psychiatric Outcomes of Girls with Attention Deficit Hyperactivity Disorder: 11-Year Follow-Up in a Longitudinal Case-Control Study. The American Journal of Psychiatry, 167, 409-417. http://dx.doi.org/10.1176/appi.ajp.2009.09050736

[9] Bederman, J., Monuteaux, M.C., Mick, E., Spencer, T., Wilens, T.E., Silva, J.M., et al. (2006) Young Adult Outcome of Attention Deficit Hyperactivity Disorder: A Controlled 10-Year Follow-Up Study. Psychological Medicine, 36, 167179. http://dx.doi.org/10.1017/S0033291705006410

[10] Murphy, K. (1994) Guarding against Over-Diagnosis of AD/HD in Adult. The ADHD Report, 2, 3-4.

[11] Pliszka, S.R. (2007) Pharmacologic Treatment of Attention-Deficit/Hyperactivity Disorder: Efficacy, Safety and Mechanisms of Action. Neuropsychology Review, 17, 61-72. http://dx.doi.org/10.1007/s11065-006-9017-3

[12] Makris, N., Biederman, J., Monuteaux, M.C. and Seidman, L.J. (2009) Towards Conceptualizing a Neural SystemsBased Anatomy of Attention-Deficit/Hyperactivity Disorder. Developmental Neuroscience, 31, 36-49. http://dx.doi.org/10.1159/000207492

[13] Rubia, K., Overmeyer, S., Taylor, E., Brammer, M., Williams, S.C., Simmons, A. and Bullmore, E.T. (1999) Hypofrontality in Attention Deficit Hyperactivity Disorder during Higher-Order Motor Control: A Study with Functional MRI. The American Journal of Psychiatry, 156, 891-896.

[14] Castellanos, F.X., Giedd, J.N., Eckburg, P., Marsh, W.L., Vaituzis, A.C., Kaysen, D., Hamburger, S.D. and Rapoport, J.L. (1994) Quantitative Morphology of the Caudate Nucleus in Attention Deficit Hyperactivity Disorder. The Ameri- 
can Journal of Psychiatry, 151, 1791-1796.

[15] Castellanos, F.X., Giedd, J.N., Marsh, W.L., Hamburger, S.D., Vaituzis, A.C., Dickstein, D.P., et al. (1996) Quantitative Brain Magnetic Resonance Imaging in Attention-Deficit Hyperactivity Disorder. JAMA Psychiatry, 53, 607-616. http://dx.doi.org/10.1001/archpsyc.1996.01830070053009

[16] Castellanos, F.X., Giedd, J.N., Berquin, P.C., Walter, J.M., Sharp, W., Tran, T., et al. (2001) Quantitative Brain Magnetic Resonance Imaging in Girls with Attention-Deficit/Hyperactivity Disorder. JAMA Psychiatry, 58, 289-295. http://dx.doi.org/10.1001/archpsyc.58.3.289

[17] Castellanos, F.X., Lee, P.P., Sharp, W., Jeffries, N.O., Greenstein, D.K., Clasen, L.S., et al. (2002) Developmental Trajectories of Brain Volume Abnormalities in Children and Adolescents with Attention-Deficit/Hyperactivity Disorder. JAMA: The Journal of the American Medical Association, 288, 1740-1748. http://dx.doi.org/10.1001/jama.288.14.1740

[18] Castellanos, F.X., Sharp, W.S., Gottesman, R.F., Greenstein, D.K., Giedd, J.N. and Rapoport, J.L. (2003) Anatomic Brain Abnormalities in Monozygotic Twins Discordant for Attention Deficit Hyperactivity Disorder. The American Journal of Psychiatry, 160, 1693-1696. http://dx.doi.org/10.1176/appi.ajp.160.9.1693

[19] Filipek, P.A., Semrud-Clikeman, M., Steingard, R.J., Renshaw, P.F., Kennedy, D.N. and Biederman, J. (1997) Volumetric MRI Analysis Comparing Subjects Having Attention-Deficit/Hyperactivity Disorder with Normal Controls. Neurology, 48, 589-601. http://dx.doi.org/10.1212/WNL.48.3.589

[20] Hynd, G.W., Hern, K.L., Novey, E.S., Eliopulos, D., Marshall, R., Gonzalez, J.J. and Voeller, K.K. (1993) Attention Deficit-Hyperactivity Disorder and Asymmetry of the Caudate Nucleus. Journal of Child Neurology, 8, 339-347. http://dx.doi.org/10.1177/088307389300800409

[21] Mataró, M., Garcia-Sánchez, C., Junqué, C., Estévez-González, A. and Pujol, J. (1997) Magnetic Resonance Imaging Measurement of the Caudate Nucleus in Adolescents with Attention-Deficit Hyperactivity Disorder and Its Relationship with Neuropsychological and Behavioral Measures. Archives of Neurology, 54, 963-968.

[22] Semrud-Clikeman, M., Filipek, P.A., Biederman, J., Steingard, R., Kennedy, D., Renshaw, P. and Bekken, K. (1994) Attention-Deficit Hyperactivity Disorder: Magnetic Resonance Imaging Morphometric Analysis of the Corpus Callosum. Journal of the American Academy of Child and Adolescent Psychiatry, 33, 875-881. http://dx.doi.org/10.1097/00004583-199407000-00014

[23] Seidman, L.J., Valera, E.M. and Makris, N. (2005) Structural Brain Imaging of Attention-Deficit/Hyperactivity Disorder. Biological Psychiatry, 57, 1263-1272. http://dx.doi.org/10.1016/j.biopsych.2004.11.019

[24] Durston, S., Hulshoff Pol, H.E., Schnack, H.G., Buitelaar, J.K., Steenhuis, M.P., Minderaa, R.B., et al. (2004) Magnetic Resonance Imaging of Boys with Attention-Deficit/Hyperactivity Disorder and Their Unaffected Siblings. Journal of the American Academy of Child and Adolescent Psychiatry, 43, 332-340. http://dx.doi.org/10.1097/00004583-200403000-00016

[25] Hill, D.E., Yeo, R.A., Campbell, R.A., Hart, B., Vigil, J. and Brooks, W. (2003) Magnetic Resonance Imaging Correlates of Attention-Deficit/Hyperactivity Disorder in Children. Neuropsychology, 17, 496-506. http://dx.doi.org/10.1037/0894-4105.17.3.496

[26] Berquin, P.C., Giedd, J.N., Jacobsen, L.K., Hamburger, S.D., Krain, A.L., Rapoport, J.L. and Castellanos, F.X. (1998) Cerebellum in Attention-Deficit Hyperactivity Disorder: A Morphometric MRI Study. Neurology, 50, 1087-1093. http://dx.doi.org/10.1212/WNL.50.4.1087

[27] Bussing, R., Zima, B.T., Gary, F.A. and Garvan, C.W. (2002) Use of Complementary and Alternative Medicine for Symptoms of Attention-Deficit Hyperactivity Disorder. Psychiatric Services, 53, 1096-1102. http://dx.doi.org/10.1176/appi.ps.53.9.1096

[28] Motofsky, S.H., Reiss, A.L., Lockhart, P. and Denckla, M.B. (1998) Evaluation of Cerebellar Size in Attention-Deficit Hyperactivity Disorder. Journal of Child Neurology, 13, 434-439. http://dx.doi.org/10.1177/088307389801300904

[29] Fassbender, C. and Schweitzer, J.B. (2006) Is There Evidence for Neural Compensation in Attention Deficit Hyperactivity Disorder? A Review of the Functional Neuroimaging Literature. Clinical Psychology Review, 26, 445-465. http://dx.doi.org/10.1016/j.cpr.2006.01.003

[30] Kim, B.N., Lee, J.S., Shin, M.S., Cho, S.C. and Lee, D.S. (2002) Regional Cerebral Perfusion Abnormalities in Attention Deficit/Hyperactivity Disorder. Statistical Parametric Mapping Analysis. European Archives of Psychiatry and Clinical Neuroscience, 252, 219-225. http://dx.doi.org/10.1007/s00406-002-0384-3

[31] Fox, P.T. and Raichle, M.E. (1986) Focal Physiological Uncoupling of Cerebral Blood Flow and Oxidative Metabolism during Somatosensory Stimulation in Human Subjects. Proceedings of the National Academy of Sciences of the United States of America, 83, 1140-1144. http://dx.doi.org/10.1073/pnas.83.4.1140

[32] Kessler, R.C., Adler, L., Ames, M., Demler, O., Faraone, S., Hiripi, E., et al. (2005) The World Health Organization Adult ADHD Self-Report Scale (ASRS): A Short Screening Scale for Use in the General Population. Psychological 
Medicine, 35, 245-256. http://dx.doi.org/10.1017/S0033291704002892

[33] Suto, T., Fukuda, M., Ito, M., Uehara, T. and Mikuni, M. (2004) Multichannel Near-Infrared Spectroscopy in Depression and Schizophrenia: Cognitive Brain Activation Study. Biological Psychiatry, 55, 501-511. http://dx.doi.org/10.1016/j.biopsych.2003.09.008

[34] Henry, J.D. and Crawford, J.R. (2004) A Meta-Analytic Review of Verbal Fluency Performance Following Focal Cortical Lesions. Neuropsychology, 18, 284-295. http://dx.doi.org/10.1037/0894-4105.18.2.284

[35] Cabeza, R. and Nyberg, L. (2000) Imaging Cognition II: An Empirical Review of 275 PET and fMRI Studies. Journal of Cognitive Neuroscience, 12, 1-47. http://dx.doi.org/10.1162/08989290051137585

[36] Elfgren, C.I. and Risberg, J. (1998) Lateralized Frontal Blood Flow Increases during Fluency Tasks: Influence of Cognitive Strategy. Neuropsychologia, 36, 505-512. http://dx.doi.org/10.1016/S0028-3932(97)00146-2

[37] Strangman, G., Boas, D.A. and Sutton, J.P. (2002) Non-Invasive Neuroimaging Using Near-Infrared Light. Biological Psychiatry, 52, 679-693. http://dx.doi.org/10.1016/S0006-3223(02)01550-0

[38] Hoshi, Y., Kobayashi, N. and Tamura, M. (2001) Interpretation of Near-Infrared Spectroscopy Signals: A Study with a Newly Developed Perfused Rat Brain Model. Journal of Applied Physiology, 90, 1657-1662.

[39] Schecklmann, M., Ehlis, A.C., Plichta, M.M., Romanos, J., Heine, M., Boreatti-Hümmer, A., et al. (2008) Diminished Prefrontal Oxygenation with Normal and Above-Average Verbal Fluency Performance in Adult ADHD. Journal of Psychiatric Research, 43, 98-106. http://dx.doi.org/10.1016/j.jpsychires.2008.02.005

[40] Ehlis, A.C., Bähne, C.G., Jacob, C.P., Herrmann, M.J. and Fallgatter, A.J. (2008) Reduced Lateral Prefrontal Activation in Adult Patients with Attention-Deficit/Hyperactivity Disorder (ADHD) during a Working Memory Task: A Functional Near-Infrared Spectroscopy (fNIRS) Study. Journal of Psychiatric Research, 42, 1060-1067. http://dx.doi.org/10.1016/j.jpsychires.2007.11.011 
Scientific Research Publishing (SCIRP) is one of the largest Open Access journal publishers. It is currently publishing more than 200 open access, online, peer-reviewed journals covering a wide range of academic disciplines. SCIRP serves the worldwide academic communities and contributes to the progress and application of science with its publication.

Other selected journals from SCIRP are listed as below. Submit your manuscript to us via either submit@scirp.org or Online Submission Portal.
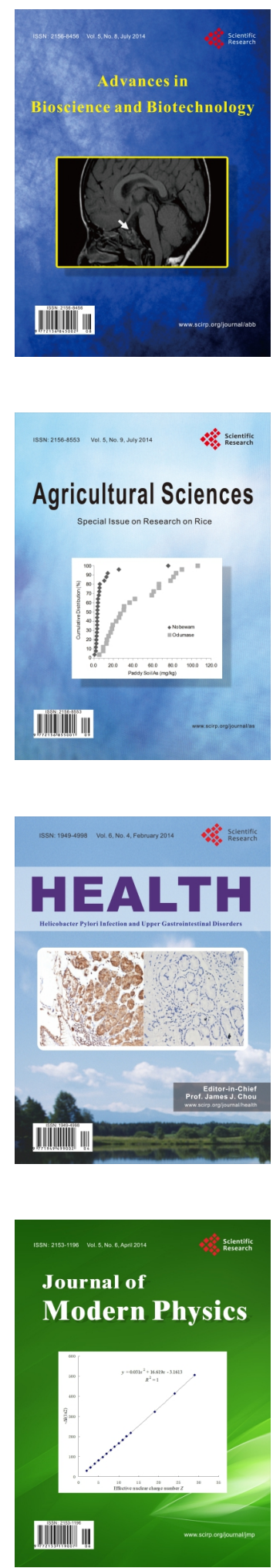
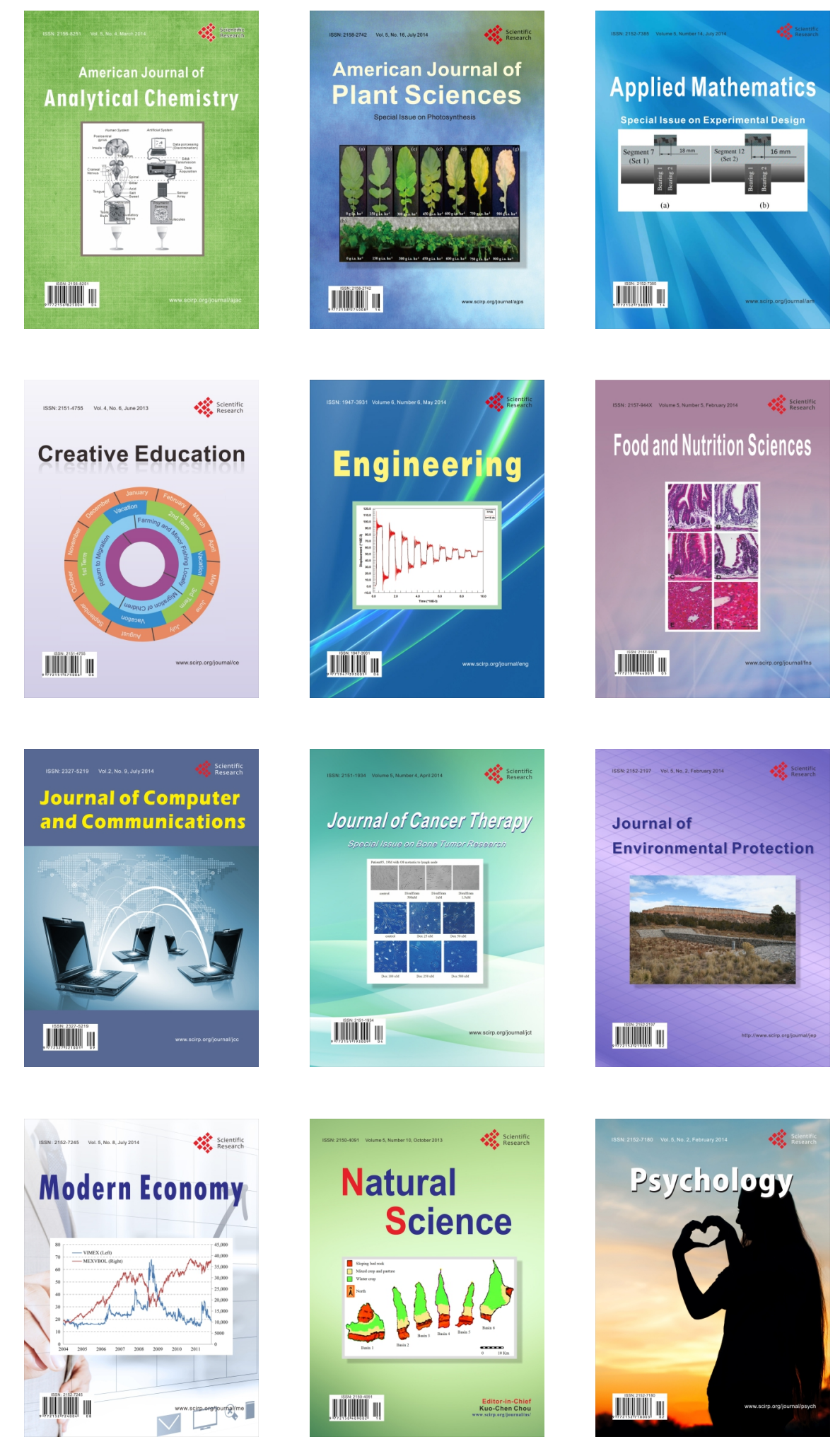